\title{
Equity in Health Benefit Utilization and Financial Risk Protection in Outpatient and Inpatient Care: Baseline Survey of Two Socioeconomic Groups of a Pilot Primary Care Benefits Scheme in the Catchment Areas of a University-Based Health Facility
}

\author{
Jose Rafael A. Marfori, ${ }^{1}$ Antonio Miguel L. Dans, ${ }^{2}$ Mica Olivine C. Bastillo, ${ }^{1}$ \\ Ramon Pedro P. Paterno, ${ }^{3}$ Mia P. Rey, ${ }^{4}$ Jesusa T. Catabuii ${ }^{1}$ and Edna Estifania A. Co ${ }^{5}$ \\ ${ }^{1}$ Philippine Primary Care Studies, University Health Service, University of the Philippines Diliman, Quezon City \\ ${ }^{2}$ Adult Medicine Research Unit, Department of Medicine, College of Medicine and Philippine General Hospital, University of the Philippines Manila \\ ${ }^{3}$ Universal Health Care Study Group, University of the Philippines Manila \\ ${ }^{4}$ Virata School of Business, University of the Philippines Diliman, Quezon City \\ ${ }^{5}$ Centre International de Formation des Autorites et Leaders (CIFAL Philippines), University of the Philippines Diliman, Quezon City
}

\begin{abstract}
Background. Health inequities in the Philippines are driven by health workforce maldistribution and health system fragmentation. These can be addressed by strengthening primary care through central social health insurance (PhilHealth) coverage. However, high reported PhilHealth population coverage and health provider accreditation have not necessarily increased health benefit utilization or financial risk protection.

Objective. This study aims to examine the impact of an enhanced, comprehensive primary care benefits package at a university-based health facility. This paper reports baseline utilization of health services and health benefits, and out-of-pocket health spending in two socioeconomic strata of the catchment population, for outpatient and inpatient services.
\end{abstract}

Methods. A questionnaire-guided survey was done among randomly selected faculty (higher income group) and non-faculty (lower income group) employees to determine the frequencies and costs of using outpatient and inpatient health services, and amounts paid out-of-pocket.

Results. Annually, both groups had approximately 1 consultation/patient and about 15 hospitalizations per 100 families annually. For hospitalizations, non-faculty inpatients utilized health insurance more frequently than faculty inpatients (75.7\% vs. 66.7\%), but paid higher out-of-pocket proportions (73.3\% or Php 92,479 /hospitalization vs. $57.4 \%$ or Php 16,273/hospitalization). For outpatient care, health benefit utilization rates were higher among non-faculty ( $12.4 \%$ vs $2.1 \%$ of consultations) although low overall, with similar total (Php 2,319 vs Php 1,741) and out-of-pocket expenses (100\%).

Conclusion. These findings confirm inequities in accessing outpatient and inpatient health services and utilizing health insurance benefits in the target population.

Key Words: primary care, primary health care, financial risk protection, out of pocket, benefit utilization, health equity, health insurance, health care services, equitable access

Corresponding author: Jose Rafael A. Marfori, MD, MPH

Philippine Primary Care Studies, University Health Service

Laurel Avenue, University of the Philippines Diliman, Quezon City 1101, Philippines

Office of the Director

Philippine General Hospital, Taft Avenue, Manila 1000, Philippines

Telephone: +6325548400 local 2099

Email: raffymarfori@gmail.com 


\section{INTRODUCTION}

\section{Inequities in Health}

The Philippine health care system is characterized by inequities in health. In richer provinces compared to poorer ones, life expectancy is over 10 years longer. ${ }^{1,2,3}$ The poorest quintile of Filipinos suffers significantly higher neonatal, infant, under-5 and child mortality rates than the richest quintile, and higher percentages of births unattended by skilled providers. ${ }^{4}$

One major reason for these inequities is a difference in access to healthcare. High accreditation and population coverage rates by PhilHealth, the national social health insurance corporation, do not necessarily translate to the utilization of health benefits or financial risk protection. PhilHealth accounts for only $14 \%$ of total national health expenses against a target of $30 \%,{ }^{5}$ leaving most (55.8\%) health expenditures to be shouldered out-of-pocket even accounting for other forms of insurance. ${ }^{6}$ Despite 92\% population coverage in 2015, PhilHealth utilization has consistently lagged behind in the poorest quintile compared to the richest, respectively at $18 \%$ versus $33 \%$ in $2003,{ }^{7}$ increasing in disparity to $33 \%$ versus $88 \%$ in $2013 .{ }^{8,4}$

\section{Health System Problems Contributing to Health Inequity}

Significant health system fragmentation and health workforce maldistribution contribute to these health inequities.

1. Administrative decentralization has led to substantial variation in governance and health service capacities in local government units (LGU). ${ }^{9,10}$ Because of inadequacies in healthcare in these local units, patients often bypass primary care. ${ }^{3}$ Healthcare efforts are also fragmented at the national level. Among at least 68 national health programs listed, some are defined by health issues and others by interventions or populations. ${ }^{11}$

2. Based on existing data, ${ }^{12,13}$ private sector doctors, nurses, and midwives outnumber their public sector counterparts by about 21 to 1,99 to 1 , and 3 to 1 respectively. Yet about $66.3 \%$ of Filipinos seek medical care from public health facilities, peaking at $89.6 \%$ among the poorest quintile. ${ }^{14}$ Using WHO recommended thresholds of health workforce to population ratios,${ }^{15}$ these estimates suggest government facilities lack roughly 60,000 doctors, 121,000 nurses and 109,000 midwives whereas the private sector has an excess of 30,000 physicians and 429,000 nurses, lacking only 9,000 midwives.

\section{The Need to Strengthen Primary Care}

A strengthened primary care system can help address inequities in health outcomes and access, and help integrate health service provision. Primary care providers have four functions: first contact care, continuity of care, comprehensive care, and coordinated care. ${ }^{16}$ Numerous countries implement a primary care system, with varying degrees of strength and insurance coverage.

Primary care, compared to more specialized healthcare, is associated with a more equitable distribution of health in populations. ${ }^{17}$ There are significant inverse associations between the strength of a country's primary care system and all-cause mortality, all-cause premature mortality and causespecific premature mortality from certain diseases. ${ }^{17}$

Integration and efficiency gains are also reasonable to expect with stronger primary care. In the United Kingdom, where general practitioners (GPs) have functioned as the gateway to more complex care since 1948, 19 out of 20 consultations were found to be resolved at the primary care level without the need for referral to secondary care. ${ }^{18}$

In the Philippines, primary care is inadequately developed. ${ }^{3}$ As in neighboring countries, it suffers from public perceptions that specialized care is superior. In addition, the diseases and populations covered are limited. Since 2000, PhilHealth has introduced outpatient benefit packages covering selected health needs such as maternal care, HIV, and tuberculosis. More recently, packages for the poorest Filipinos were introduced covering seven laboratory tests plus treatments and services for a handful of conditions.

Building on these efforts, existing health systems may shift from disease-based or intervention-based packages towards insuring first-contact comprehensive and continuing care. This is being piloted at the University Health Service (UHS) of the University of the Philippines, Diliman campus.

\section{Objectives}

To assess the effect of such a shift on equitable healthcare utilization, a baseline survey was conducted prior to the pilot program at the UHS. This paper reports on 1) the baseline utilization of outpatient and inpatient health services and health benefits, and 2) related health spending of the catchment population including financial protection from social health insurance.

\section{METHODS}

A cross-sectional survey was carried out using questionnaire guided face-to-face interviews of faculty and non-faculty employees representing themselves and their dependents, chosen by single-stage cluster random sampling. Verbal informed consent was obtained from respondents, as the survey was a systems standard procedure for quality control as part of feedback agreed upon with the community during the preparation phase of the study. Only the researchers had access to the data forms, which were kept securely and anonymized for processing. Each respondent represented their family, meaning healthcare utilization and expenses from other family members were 
counted. This is consistent with prevailing patterns of social health insurance based on family units. The definition of "dependents" differed slightly between the pilot clinic and PhilHealth. The broader definition was used to capture respondents' actual use or non-use of health benefits.

Within a family there may be more than 1 consultation or hospitalization, by one or multiple family members. Each instance of consultation or hospitalization was counted separately. Admission diagnoses and hospitals of admission were also quantified. Multiple admission diagnoses in the same hospitalization were counted separately, as were multiple admissions at the same hospital by members of the same family.

\section{Random Sample Generation}

The intended beneficiaries of the proposed pilot program are 5,017 university employees, contractual, and faculty, plus an estimated 2 dependents each, or a total of 15,051 individuals. A sample size of 357 with a confidence interval of $+/-5 \%$ at a significance level of $p \leq 0.05$ was obtained using a sample size calculator (www.surveysystem. com). Three hundred fifty-seven (357) university employees, contractual, and faculty were randomly selected from the latest official list and interviewed in person. Students as well as workers employed or contracted by agencies other than the university were excluded from this survey, as they would not be covered by the corporate clinic pilot study.

\section{Preparation of Questionnaire}

A utilization, hospitalization and financial risk protection questionnaire was created to assess outpatient and inpatient expenses for consults, laboratory tests and medicines. Questions were asked on the frequency of outpatient visits and inpatient care, choice of facility and health professional, and overall and out-of-pocket expenses. No question was asked regarding the use of health maintenance organization (HMO) plans for outpatient consults. Two percent of Filipinos are members of HMOs or are covered by private health insurance. ${ }^{4}$ Also, payments made using HMO plans are smaller and harder to recall than hospitalization bills, and are typically deducted from an annual balance. Both of these factors would hinder a 3-month recall of $\mathrm{HMO}$ costs.

Pretesting was done and required minimal modification for clarity. To minimize recall bias, recall periods of 1 year for inpatient services and 3 months for outpatient consults were set. The survey was conducted over a period of 3 months.

\section{Analysis of Results}

Data was encoded into an Excel spreadsheet and analyzed using descriptive statistics. Where appropriate, indicators were compared between outpatient and inpatient settings of care, public and private health providers, and faculty and non-faculty employment types as a proxy for income status. Educational attainment and average income were presumed to be higher among faculty than nonfaculty respondents.

Hospitalization rate (HR) was defined as the frequency at which hospitalization occurred relative to the number of families surveyed:

$$
H R=\frac{\text { number of reported hospitalizations }}{\text { number of families surveyed }(n)}
$$

There are as yet no PhilHealth outpatient benefits covering those surveyed. However, outpatient consults at the UHS are subsidized by the university as an employee benefit, similar to corporate clinic benefits for employees. Hence, outpatient benefit utilization rate in this study was defined as the proportion of consultations anywhere (at UHS or elsewhere) by eligible beneficiaries in the past 3 months that were conducted with a UHS primary care physician. Referral to UHS staff physicians from outside and transmission of medical records to them were not required to classify consultations as utilizing benefits:

$$
H R=\frac{\text { consultations with UHS primary care doctors }}{\text { consultations with any doctor, at UHS or elsewhere }(n)}
$$

Inpatient benefit utilization rate was obtained by dividing the number of admissions where PhilHealth benefits were used as payment, by all admissions in the past 12 months. This is the inverse of underutilization which is defined by the Quality Improvement Demonstration Study (QIDS) as the likelihood of not filing claims despite having legitimate insurance coverage. ${ }^{7}$

Financial risk protection (FRP) was defined in this study as the percentage of health expenses covered by PhilHealth or other insurance. Financial risk protection is computed using out-of-pocket (OOP) expenses and total expenses (which includes expenses paid OOP, by PhilHealth, and by other insurance), as shown in the formula below:

$$
\operatorname{FRP}(\%)=100 \%-\left[\frac{\text { Total OOP expenses }}{\text { Total expenses }} \times 100 \%\right]
$$

Financial risk protection is therefore inversely proportional to the percentage of total expenses that come out-of-pocket. A low out-of-pocket expense denotes high financial risk protection.

Average out-of-pocket expense per family (in PHP) was obtained by dividing the total out-of-pocket expense by the number of families who have had at least one admission in the family in the past 12 months:

\footnotetext{
Average OOP expense per family $(\mathrm{PHP})=\frac{\text { Total OOP expenses }}{\text { No. of families with } 1 \text { or more admissions in past } 12 \text { months }}$
} 
Average out-of-pocket expenses were also obtained on a per consult or per hospitalization basis, in which case the denominator was changed to either total consultations or total hospitalizations, respectively.

\section{RESULTS}

Of the 357 respondents, $90(25.2 \%)$ were faculty employees and $263(73.7 \%)$ were non-faculty employees. Four (1.1\%) respondents did not specify employment type and were excluded from the subgroup analyses but included for overall estimates. This sample distribution approximates that of the UP Diliman employee population, which consists of 1,496 (27.2\%) faculty employees and 3,996 (72.8\%) nonfaculty employees as of 2017.

\section{A. Admission and Outpatient Consultation Rates}

In the 3-month recall period, there were 282 outpatient consults with any health provider, summarized in Table 1 . About a third came from the faculty group and two thirds from the non-faculty group, whether counting consultations (95 faculties, 185 non-faculty, 2 unspecified), patients (50 faculty, 120 non-faculty, 2 unspecified) or families (47 faculties, 107 non-faculty, 2 unspecified). However, since faculty respondents represented only $25 \%$ of the sample, their consultation rate is 1.5 times that of non-faculty families. Further, $55.6 \%$ of families of faculty employees and $45.6 \%$ of families of non-faculty employees reported at least one outpatient consult in the past three months.

In the 12-month recall period, there were 53 hospitalizations of 50 individuals from 46 families, or 15 hospitalizations of 13 individuals from 13 faculty families and 37 hospitalizations of 36 individuals from 32 nonfaculty families (Table 1). There were 4 families (respondents) of unspecified employment type, who had 2 consults and 1 hospitalization.

The 53 admissions were distributed among 25 institutions, 16 private and 9 public. Most were within Metro Manila, particularly in cities near the university.
Hospitalizations reported were almost equally distributed between government ( 28 cases, or $52.8 \%$ of the total) and private hospitals $(25$, or $47.2 \%)$, most frequently at the UHS itself (8 cases, or 15.1\%). Use of public versus private facilities was similar between income groups as shown by the proportion of each income group's admissions that used either type of facility (Table 2). However, one key difference observed was that 7 of the 8 admissions at the UHS were from non-faculty families.

\section{B. Health Benefit Utilization}

Outpatient and inpatient benefit utilization rates by employee type are shown in Figure 1. Overall, 8.9\% (25 of 282) of consultations occurred at the subsidized UHS, including two by beneficiaries of unspecified employment type. Out of 95 consults by members of faculty families, only $2(2.1 \%)$ were sought at the UHS. In contrast 23 of 185 (12.4\%) non-faculty consults occurred at the UHS.

Of 53 hospital admissions, 39 (73.6\%) used inpatient PhilHealth benefits overall, or 10 among 15 faculty admissions (66.7\%) and 28 among 37 non-faculty admissions (75.7\%) (Figure 1). Overall therefore, non-faculty were marginally more likely than faculty to use PhilHealth benefits. This gap was more pronounced in private hospitals, where $88.2 \%$ of nonfaculty admissions compared to $50.0 \%$ of faculty admissions used PhilHealth benefits. However, the gap was largest and in the opposite direction at public hospitals: $100 \%$ of faculty admissions used PhilHealth benefits compared to two-thirds of non-faculty admissions (66.7\%). Given the observed non-utilization of PhilHealth inpatient benefits by large proportions of both groups, the survey instrument was modified for the follow-up surveys, to ask about the reasons for this.

\section{Financial Risk Protection (FRP)}

Average total costs and average out-of-pocket expenses for inpatient and outpatient care are shown in Table 2, including consultation fees, laboratory tests and medicines. Most of the reported health insurance used for inpatient care was social health insurance.

Table 1. Total and average number of consultations and hospitalizations per 100 families per year

\begin{tabular}{|c|c|c|c|c|}
\hline \multirow[b]{2}{*}{$\begin{array}{c}\text { Group } \\
\text { (number of families interviewed) }\end{array}$} & \multicolumn{2}{|c|}{ Outpatient consultations } & \multicolumn{2}{|c|}{ Inpatient hospitalizations } \\
\hline & $\begin{array}{l}\text { Total number } \\
\text { over } 3 \text { mos. }\end{array}$ & $\begin{array}{l}\text { Average number per } \\
100 \text { families per year }\end{array}$ & $\begin{array}{l}\text { Total number } \\
\text { over } 12 \text { mos. }\end{array}$ & $\begin{array}{l}\text { Average number (HR) per } \\
100 \text { families per year }\end{array}$ \\
\hline Faculty families $(n=90)$ & 95 & 420 & 15 & $16.7^{a}$ \\
\hline Non-faculty $(n=263)$ & 185 & 280 & 37 & $14.1^{\mathrm{a}}$ \\
\hline Overall $(n=357)$ & 282 & 316 & 53 & $14.8^{a}$ \\
\hline
\end{tabular}

a Hereafter expressed as hospitalizations per 100 families

Table 2. Distribution of hospitalizations among public and private hospitals by income group

\begin{tabular}{lcc}
\multicolumn{1}{c}{ Group } & \multicolumn{2}{c}{ Inpatient admissions } \\
\cline { 2 - 3 } \multicolumn{1}{c}{ (number of families interviewed) } & Private hospitals & Public hospitals \\
\hline Faculty families $(\mathrm{n}=90)$ & $8(53.3 \%)$ & $7(46.7 \%)$ \\
Non-faculty $(\mathrm{n}=263)$ & $17(45.9 \%)$ & $20(54.1 \%)$ \\
Overall $(\mathrm{n}=357)$ & $25(47.2 \%)$ & $28(52.8 \%)$ \\
\hline
\end{tabular}

a Including four (4) families of unspecified employment type that had one (1) admission in a public hospital 


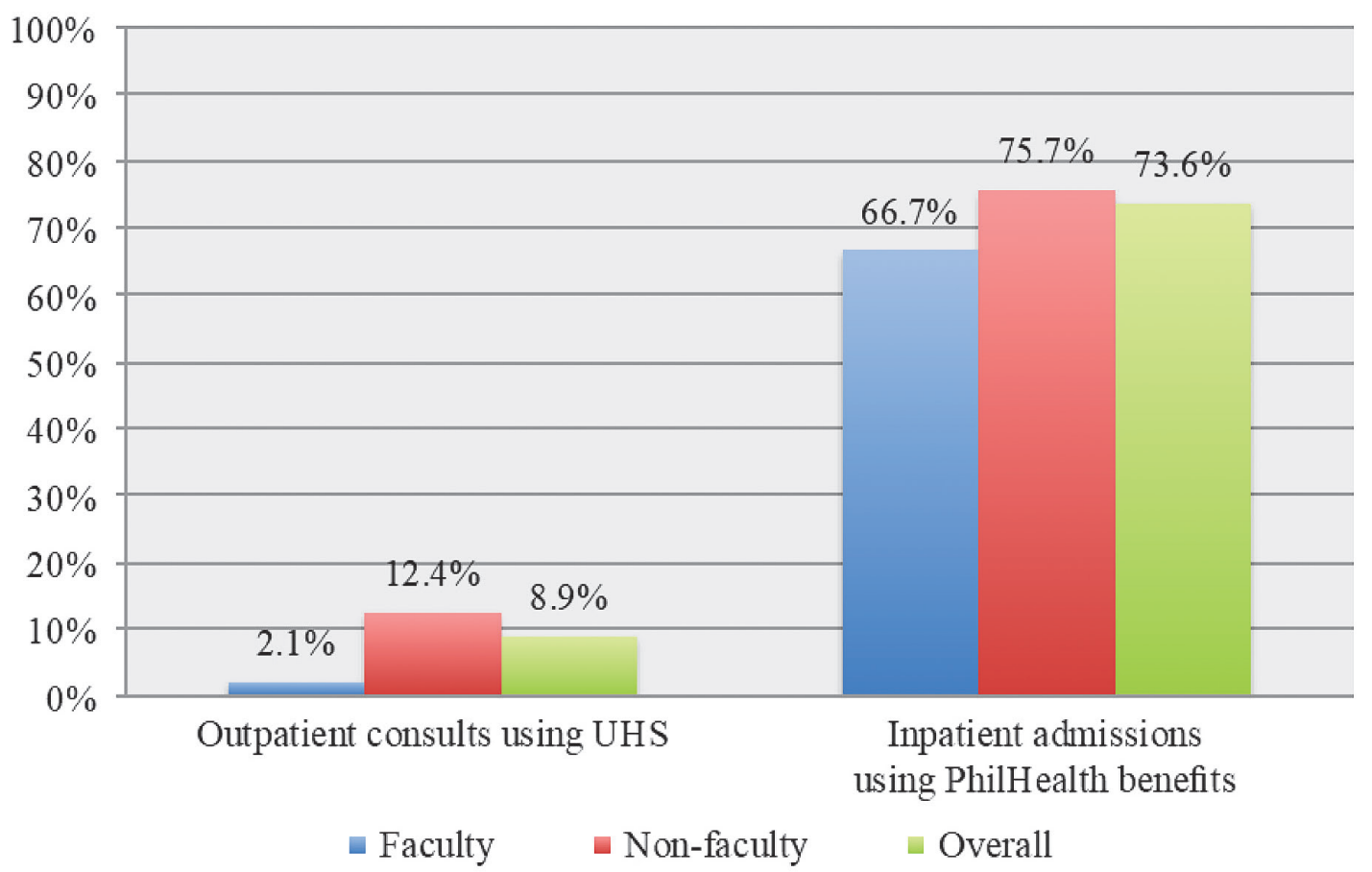

Figure 1. Proportions of outpatient consults and hospital admissions where health benefits were used, by employment type

${ }^{a}$ Health benefits consisted of subsidized employee healthcare at the UHS for outpatient care and PhilHealth insurance for inpatient care.

\section{Outpatient Care}

Because there are no PhilHealth outpatient benefits in this population, outpatient out-of-pocket expenses were seen to be $100 \%$ of total outpatient expenses (Table 3). Any subsidy from the university or coverage by HMO plans were difficult to account for due to inadequate information, but were considered to be minimal.

Interestingly, average expenses per consult were Php 2,319.21 for non-faculty but only Php 1,740.74 for faculty, a relative difference of $33 \%$ (Table 3). Chief complaints per consultation were not elicited as part of the survey. Overall, each family that consulted at least once shouldered an average of Php 3,884.25 during the 3-month recall period.

\section{Inpatient Care}

During hospital confinement, average total costs were higher for the non-faculty group (Php 126,182 compared to Php 28,353) (Table 3). Non-faculty beneficiaries paid $73.3 \%$ of their health expenditures out-of-pocket. Faculty beneficiaries did a little better, with out-of-pocket expenses amounting to only $57.4 \%$ of total health expenses (Table 3 ). The proportion of health expenses paid out-of-pocket is about $28 \%$ higher among non-faculty families whether in public hospitals or private hospitals. For the sample population as a whole, the fraction of health expenses paid OOP for private hospital admissions (86.9\%) is higher than that for public hospital admissions (59.4\%).

\section{DISCUSSION}

At a family size of 3 people per family in this population (following PhilHealth standard family size), the 357 respondents represented 1,071 family members. There were 282 consults in a 3-month recall period, averaging 1.05 consultations per person annually. This is close to the average annual ambulatory visit rate in one study in rural Viet Nam ( 0.76 consults per person), which the authors note is relatively low. ${ }^{19}$ Average ambulatory visit rates are higher in studies in rural China ( 4.4 per person $)^{20}$ where a broad range of health providers was considered, and Manitoba, Canada (4.9 per person, increasing with physician supply and health need $)^{21}$ where universal primary care is available.

The total cost of outpatient consults was Php 605,943.00 for the 3-month recall period, currently shouldered only by those who were sick at an average of Php 2,148.73 per consult. By comparison, the national average costs of treatment per visit to a health facility are Php 2,268 in private facilities and Php 455 in public facilities, or $\mathrm{Php}$ 1,044 overall. $^{4}$ Since the 282 consultations came from only 172 patients in only 156 families, the sick therefore shouldered Php 3,522.92 per patient or Php 3,884.25 per family that had any consultations. Universal primary care insurance for this sample population of 1,071 people could have financed these expenditures including professional fees, laboratory tests, and medications at contribution rates 
Table 3. Out-of-pocket expenses among faculty and non-faculty families for outpatient services over a 3-month recall period, and for inpatient care in public and private hospitals over a 12-month recall period

\begin{tabular}{|c|c|c|c|c|c|}
\hline & $\begin{array}{c}\text { Total No. of } \\
\text { Consultations or } \\
\text { Hospitalizations }\end{array}$ & $\begin{array}{c}\text { Average Total Expenses per } \\
\text { Consult or Hospitalization } \\
\text { Php }\end{array}$ & $\begin{array}{c}\text { Average OOP Expenses per } \\
\text { Consult or Hospitalization } \\
\text { Php(\%) }\end{array}$ & Std. Dev. (Php) & Min., Max. \\
\hline \multicolumn{6}{|c|}{ Outpatient (Consultations) } \\
\hline Faculty families & 95 & $1,740.73^{c, d}$ & $1,740.74(100 \%)^{g}$ & $5,399.70$ & $\begin{array}{c}100.00 \\
50,000.00\end{array}$ \\
\hline Non-faculty families & 190 & $2,319.21^{\mathrm{c}, \mathrm{d}}$ & $2,319.21(100 \%)^{g}$ & $3,685.67$ & $\begin{array}{c}15.00 \\
35,400.00\end{array}$ \\
\hline Overall & $282^{a}$ & $2,148.73^{c, d, f}$ & $2,148.73(100 \%)^{g}$ & $4,185.35$ & $\begin{array}{c}15.00 \\
50,000.00\end{array}$ \\
\hline \multicolumn{6}{|c|}{ Inpatient (Hospitalizations) } \\
\hline Faculty families & 15 & $28,353.33$ & $16,273.33(57.4 \%)$ & $11,159.87$ & $\begin{array}{c}300.00 \\
65,000.00\end{array}$ \\
\hline Non-faculty families & 37 & $126,182.08$ & $92,478.84(73.3 \%)$ & $80,845.77$ & $\begin{array}{c}800.00 \\
1,200,000.00\end{array}$ \\
\hline Overall & $53^{a, b}$ & $98,113.90^{e}$ & 70,298.43 (71.6\%) & $69,337.73$ & $\begin{array}{c}300.00 \\
1,200,000.00\end{array}$ \\
\hline
\end{tabular}

${ }^{a}$ Including four (4) subjects of unspecified employment classification that had two (2) consults.

${ }^{b}$ Including four (4) families of unspecified employment type that had one (1) admission in total.

${ }^{c}$ Total and OOP values are identical because no PhilHealth benefits exist, and HMO coverage could not be accounted for.

${ }^{d}$ These values are after subsidy from the University. The amounts subsidized would vary between patients and are not known per service (consults, laboratory and imaging tests, medications).

${ }^{e}$ These include costs recalled for one (1) admission of unspecified employment type: Php79,000 total and Php60,000 declared as OOP expenses.

${ }^{f}$ This includes Php11,520 representing the cost of two consults from families of unspecified employment type.

${ }^{g}$ Outpatient OOP values (100\%) reflect the lack of PhilHealth benefits. Outpatient OOP expenses may be lower if the use of HMO plans were accounted for. However, HMO payment mechanisms may preclude their proper recall. Prices at the UHS are subsidized by the university, but exact amounts subsidized per transaction are generally not known by respondents.

When needed, PhilHealth case rates were obtained from the PhilHealth Annex of Medical Case Rates and Revised Value Scale for Procedures, based on the given diagnosis.

of Php 565.77 per person for the 3-month period, or Php 188.60 monthly per capita.

Despite a reported 92\% PhilHealth coverage of the population in 2015, reimbursements were successfully claimed by only $12 \%$ of all eligible members. ${ }^{22}$ However, since not all members need to make claims, this proportion is difficult to interpret without an estimate of population health need. In our study a similar proportion (about 15\%) of eligible families incurred hospitalizations. Survey methods are currently necessary to estimate health needs in the absence of centralized gatekeeping and reporting from primary care.

In this survey $73.6 \%$ of inpatient cases used PhilHealth benefits, falling between benefit utilization rates of $85 \%$ in the QIDS study and $69.75 \%$ in a study among patients under 5 years of age. ${ }^{23,24}$ Hence, over a quarter of hospitalizations were not supported by any insurance, even including private insurance. Both types of insurance combined were estimated to cover only $28.4 \%$ of inpatient costs. Hence, out-ofpocket payments accounted for more than half of inpatient expenses among faculty and non-faculty alike, implying low support value of health insurance. Only a few respondents indicated the use of other health insurance, meaning most of the financial risk protection enjoyed by respondents is due to PhilHealth coverage. These figures suggest coverage or enrolment to PhilHealth does not necessarily translate to the utilization of benefits or adequate support value.
The weak financial risk protection particularly affected those of presumed lower socioeconomic status in our study, as inpatient OOP spending was 30\% higher among nonfaculty families in both public and private hospitals. This inequity is consistent with earlier studies that found poorer quintiles generally have lower utilization of PhilHealth benefits than richer ones ${ }^{25,4}$ Known predictors of PhilHealth inpatient benefit utilization include higher wealth index, being a paying rather than subsidized or indigent PhilHealth member, confinement at a private rather than public hospital and higher educational attainment of the household head. ${ }^{4,23,24}$

Our study found signs of a similar trend for outpatient health benefit utilization. Although faculty and non-faculty families are presumed to be of different income brackets, their outpatient expenses were similar. A finding of equal financial burden across unequal socioeconomic strata implies that there are inequities in access to social health insurance benefits. This, even with a higher propensity to use the subsidized services at UHS among non-faculty than faculty families ( $12.4 \%$ of consultations compared to $2.1 \%$, respectively).

In addition, lower socioeconomic status is generally associated with poorer health status and greater health needs. This disparity may partly explain why the non-faculty group incurred higher average total costs per hospital admission than did the richer group. Similarly, outpatient spending per 
consult could be higher among the poorer group, although this may require statistical analysis to interpret with certainty. Since hospitalization rates were similar in both groups, disparities in inpatient spending may be related to differences in the reasons for admission or chief complaints, which can be explored in further studies. Further studies may also explore the joint effect of variables such as socioeconomic status and the reason for admission on hospitalization costs, in order to generate a more concrete explanation of costs.

The higher percent out-of-pocket expense in private hospitals than in public hospitals is an expected finding. One reason for this may be the variability between public and private hospitals in applying the no-balance-billing policy, which prevents eligible patients from being charged anything in excess of PhilHealth-specified and covered case rates.

\section{CONCLUSION}

Baseline conditions among two employee categories prior to a pilot program of universal primary care benefits showed similar service utilization rates between groups, higher benefit utilization rates among the poorer group, and greater financial risk for the poorer group. For outpatient care, average costs were similar and FRP was equal and absent for both groups despite unequal socioeconomic strata. For inpatient care, average total costs and proportions paid out-of-pocket were higher among the poorer group. These results suggest inequities in access to outpatient and inpatient care benefits are present.

Health service utilization rates were roughly equivalent between non-faculty and faculty groups (1 consultation/ person/year and 15 hospitalizations/100 families/year). Proxy outpatient benefit utilization rates were low $(8.9 \%$ of consults overall) although higher for the poorer group than the richer group (12.4\% and 2.1\%). Benefits were utilized for $73.6 \%$ of hospitalizations overall, again higher for the poorer group (75.7\% and 66.7\%).

Both groups incurred similar average costs for outpatient care (Php 2,149/consultation), lacking any financial risk protection since there are no universal primary care benefits. Average hospitalization costs were higher for the poorer group (Php 126,182 compared to Php 28,353). Inpatient financial risk protection is undermined by low support value of $28.4 \%$, leaving $71.6 \%$ of costs to be shouldered out-ofpocket, particularly affecting the poorer group $(73.3 \%$ vs. $57.4 \%$ out-of-pocket spending).

\section{Acknowledgments}

The authors wish to thank Rhodora N. Aquino, Kristine O. Cenizal, Wayne L. Manuel, and the entire staff of the University Health Service of the University of the Philippines for their valuable contribution.

\section{Statement of Authorship}

All authors have approved the final version submitted.

\section{Author Disclosure}

All authors declare no conflict of interest. The authors had full access to all data in this study. The Philippine Health Insurance Corporation requested that only active PhilHealth members be included in the study. Funders had no other role in study design; collection, analysis, and interpretation of data; writing of the report; or the decision to submit the report for publication.

\section{Funding Source}

This work was supported by the University of the Philippines Emerging Interdisciplinary Research (EIDR) program [grant number $\mathrm{C} 07-001$ ] and the Philippine Health Insurance Corporation.

\section{REFERENCES}

1. Epidemiology Bureau, Department of Health [Internet]. 2015. Philippine Health Statistics 2013. Manila, Philippines: Department of Health. [cited 2017]. Available from http://www.doh.gov.ph/sites/ default/files/publications/2013PHScompressed_0.pdf

2. Health Intelligence Service, Department of Health [Internet]. 1989. Philippine Health Statistics 1987. Manila, Philippines: Department of Health. [cited 2017]. Available from http://www.doh.gov.ph/sites/ default/files/publications/PHS1987a.pdf

3. Romualdez AJG, dela Rosa JFE, Flavier JDA, et al. The Philippines health system review (Vol. 1). Geneva: WHO Press. 2011.

4. Philippine Statistics Authority (PSA) [Philippines], and ICF International [Internet]. 2014. Philippines National Demographic and Health Survey 2013. Manila, Philippines, and Rockville, Maryland, USA: PSA and ICF International. [cited 2017]. Available from https:// dhsprogram.com/pubs/pdf/FR294/FR294.pdf

5. UPecon Health Policy Development Program [Internet]. 2016. Who Pays and Who Benefits from Health Sector Reforms? (A quick look at the last 25 years) (Draft for comments). [cited 2017]. Available from http://www.econ.upd.edu.ph/ayala-upse/wp-content/ uploads/2016/04/Text-9th-Ayala_UPSE-Forum-Who-Pays-andWho-Benefits-from-Health-Care-Reforms-07Apr16-ANH.pdf

6. Bersales L. Each Pinoy spent 5,859 for health in 2014 [Internet]. 2016. Philippine Statistics Authority. [cited 2017 April]. Available from https://psa.gov.ph/national-health-accounts-press-releases

7. Quimbo SA, Kraft AD, Capuno JJ. Health, education and the household: Explaining poverty webs (Discussion Paper No. 0809) [Internet]. 2008. Quezon City, Philippines: School of Economics, University of the Philippines.

8. Faraon EJA, Estrada JAG, Farillas ELF, et al. Significant predictors of underutilization of inpatient benefits among PhilHealth members in selected barangays in Manila. Acta Med Philipp [Internet]. 2013 [cited 2017]; 47(3):69-73. Available from http://actamedicaphilippina.com. $\mathrm{ph} /$ sites/default/files/fulltexts/vol-47-no-3-significant.pdf

9. National Statistical Coordination Board [Internet]. c2009. Provincial Good Governance Index for 2005 and 2008 by Region. National Statistical Coordination Board, Philippine Statistics Authority. [cited 2017]. Available from http://nap.psa.gov.ph/ggi/ ProvincialGGI_2005_2008_NSCB.pdf

10. Silfverberg RR. The Sponsored Program of the Philippine National Health Insurance-Analyses of the actual coverage and variations across regions and provinces (Discussion Paper No. 2014-19) [Internet]. 2014. Philippine Institute for Development Studies. [cited 2017]. Available from http://dirp3.pids.gov.ph/webportal/CDN/PUBLICATIONS/ pidsdps1419.pdf

11. Department of Health [Internet]. (n.d.). Programs A-Z | Department of Health website. [cited 2017 May 10]. Available from http://www. doh.gov.ph/health-programs 
12. Health Human Resource Development Bureau, Department of Health [Internet]. (n.d.). National Database of Selected Human Resources for Health. [cited 2018 January 20]. Available from http://www.ndhrhis. com/s.reports.archive.php

13. Professional Regulation Commission (PRC), Manila, Philippines [Internet]. (n.d.). Official Website of the PRC July 21, 2014. [cited 2017]. Available from http://www.prc.gov.ph/

14. Department of Health [Internet]. 2012. National Objectives for Health, 2011-2016. Manila, Philippines: Department of Health. [cited 2017]. Available from http://www.doh.gov.ph/content/nationalobjectives-health-2011-2016.html

15. Campbell J, Dussault G, Buchan J, et al. A universal truth: no health without a workforce (Forum Report) [Internet]. 2013. Geneva: Global Health Workforce Alliance and World Health Organisation. [cited 2017]. Available from http://www.who.int/workforcealliance/ knowledge/resources/GHWA-a_universal_truth_report.pdf?ua $=1$

16. American Academy of Family Physicians [Internet]. (n.d.). Primary Care. [cited 2017 February 17]. Available from https://www.aafp.org/ about/policies/all/primary-care.html

17. Macinko J, Starfield B, Shi L. The contribution of primary care systems to health outcomes within Organization for Economic Cooperation and Development (OECD) Countries, 1970-1998. Health Serv Res. 2003; 38(3):831-65. https://doi.org/10.1111/1475-6773.00149

18. Goodwin N, Dixon A, Poole T, Raleigh V, Gao H, Lyscom T. The Evolving Role and Nature of General Practice in England [Internet]. 2011. In improving the quality of care in general practice: report of an independent inquiry commissioned by the king's fund. london: the king's fund. [cited 2017]. Available from https://www.kingsfund. org.uk/sites/default/files/improving-quality-of-care-general-practiceindependent-inquiry-report-kings-fund-march-2011_0.pdf
19. Segall M, Tipping G, Lucas $H$, et al. Economic transition should come with a health warning: the case of Vietnam. J Epidemiol Community Health. 2002; 56(7):497-505. https://doi.org/10.1136/jech.56.7.497

20. Hao V, Suhua C, Lucas H. Equity in the utilization of medical services: a survey in poor rural China [Internet]. 1997. [cited 2017]. Available from https://opendocs.ids.ac.uk/opendocs/bitstream/handle/1234567 89/11603/j.1759-5436.1997.mp28001003.x.pdf?sequence=1

21. Martens P, Bond R, Jebamani L, et al. The Health and Health Care Use of Registered First Nations People Living in Manitoba: A Population-Based Study [Internet]. 2002. Manitoba, Canada: Manitoba Centre for Health Policy, University of Manitoba. [cited 2017]. Available from https://pdfs.semanticscholar.org/e4af/ d4bdd5e1a69a2cddc6e5c2cc389602a78dbf.pdf

22. Philippine Health Insurance Corporation [Internet]. 2015. Stats \& Charts January-December 2015. Philippine Health Insurance Corporation. [cited 2017]. Available from https://www.philhealth.gov. ph/about_us/statsncharts/snc2015_2nd.pdf

23. Puyat MEAD. Factors Influencing PhilHealth Coverage and In-Patient Benefit Utilization of Filipino Children Under Five (Discussion Paper No. 2013-37) [Internet]. 2013. Philippine Institute for Development Studies. [cited 2017]. Available from https://dirp4. pids.gov.ph/ris/dps/pidsdps1337.pdf

24. Quimbo SA, Florentino J, Peabody JW, Shimkhada R., Panelo C, Solon O. Underutilization of Social Insurance among the Poor: Evidence from the Philippines. PLoS ONE. 2008; 3(10):e3379. https://doi.org/10.1371/journal.pone.0003379

25. National Epidemiology Center, Department of Health [Internet]. 2012. The 2010 Philippine Health Statistics. Manila, Philippines: Department of Health. [cited 2017]. Available from http://www.doh.gov.ph/ sites/default/files/publications/PHS2010_March13.compressed.pdf

The Acta Medica Philippina is now accepting original scientific papers, review articles and case reports for its upcoming issues. Please follow the format for submission as indicated in the "Instructions to Authors" elsewhere in the journal. All papers received shall be properly acknowledged. For inquiries and submission of proposals, please e-mail us at actamedicaphilippina@yahoo.com 